\title{
Dissolution of silver nanoparticles in presence of natural organic matter
}

\author{
Zhang Linlin ${ }^{*}$, Kulukawa Tanaka ${ }^{2}$ \\ ${ }^{1}$ Department of Chemistry, Jinan Vocational College, Jinan, Shandong 250000, China \\ ${ }^{2}$ Department of Chemistry, Daiichi Institute of Technology 110005, Japan \\ "Corresponding author. Tel: (+86) 18115334325; E-mail: chenshaofeng@rocketmail.com
}

Received: 13 July 2013, Revised: 12 August 2013 and Accepted: 18 August 2013

\section{ABSTRACT}

This study investigated the dissolution kinetics of silver nanoparticles in presence of natural organic matter. Silver nanoparticles were synthesized using chemical reduction method. Particle size and surface charges of the synthesized silver nanoparticles were characterized using a zetasizer. ICP-MS combined with ultrafiltration technology was used to quantify the silver nanoparticle dissolution in presence of natural organic matters. The obtained results suggested that the dissolution rate of silver nanoparticles decreases with increasing natural organic matter content. Our study provides important guidance in elucidating the transport and fate of silver nanoparticles in natural water conditions. Copyright (C) 2014 VBRI press.

Keywords: Dissolution kinetics; silver nanoparticle; natural organic matter; zeta potential.

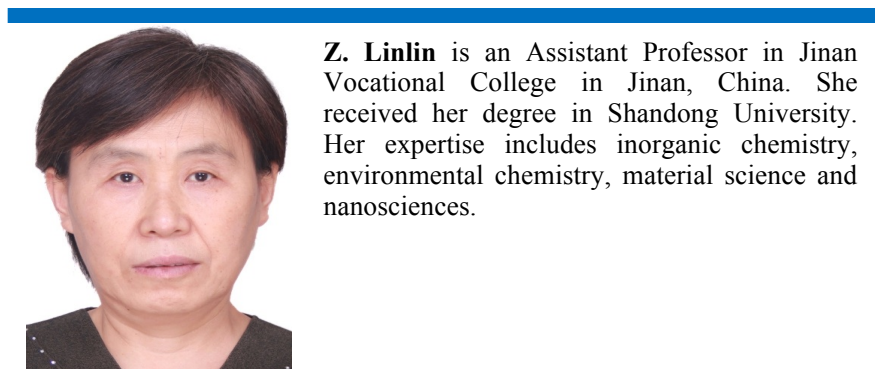

\section{Introduction}

Silver nanoparticles (AgNP) were extensively studied because of its potential applications due to their antimicrobial properties [1-8]. In 2010, commercial products containing $\mathrm{nAg}$ are among the mostly used nanomaterials around the world.

The elucidated antimicrobial mechanism suggested that AgNPs can be transported on the cell membrane and can pit on the membrane thus hurt its permeability [2-5]. Other mechanisms suggested that ionic silver can be released and cause cell death by interacting with the sulfur containing proteins [3]. Reactive oxygen species, such as peroxides and oxygen ions, which were generated by light irritation, can also hurt cells by causing oxidative stress $[2,3]$.

Previous studies have reported that AgNP could be toxic to microorganisms in various water conditions $[3,4]$. However, changes in physicochemical properties can result in changes in toxicity of AgNP. For example, it was indicated that particle size can be related to changes in toxicity in multiple publications. Other physicochemical parameters studied include zeta potential and dissolution of AgNP. The release of AgNP into natural water can harm or kill naturally occurring microorganism communities. Therefore it is important to study the physicochemical properties of AgNP in natural waters. Specifically, fate of AgNP in presence of natural organic matter (NOM) was investigated in this study [9-15]. NOM is ubiquitous in most of the surface natural water systems. Although previous studies have investigated the effect of $\mathrm{pH}$, ionic strength, dissolved oxygen, and particle size on the dissolution of AgNP [15-21], studies on the dissolution of AgNP in presence of NOM are still rare.

In this study, AgNP was synthesized by chemical reduction method. The morphology of AgNP was characterized using transmission electron microscopy. Average hydrodynamic size was measured using dynamic light scattering (DLS) technique. Surface charge of AgNP was measured in term of zeta potential using a zetasizer. Dissolution of $\mathrm{nAg}$ was measured as total silver by inductively coupled plasma mass spectrometry (ICP-MS). The result of this study provided important information on the physicochemical property of AgNP, which is vitally important for their toxicological evaluation in aquatic systems.

\section{Experimental}

Nanosilver synthesis

AgNP was synthesized via chemical reduction method. In this study, maltose was chosen to be the reducing agent 
which can reduce the ionic silver into elemental form. The nanoparticle synthesis procedure followed previously published procedure [9]. $\mathrm{pH}$ value of the reaction system was adjusted to 11.5 using $\mathrm{NaOH}$. Then, PVP was added as capping agent. PVP was used in this study because it is frequently used by other researchers which allow us to compare results. The obtained $\mathrm{nAg}$ solutions were cleaned with deionized (DI) water using a $3 \mathrm{kDa}$ nominal molecular weight cut-off (NMWCO) ultrafiltration membrane manufactured by Millipore. TEM was used to characterize the shape of $\mathrm{nAg}$. Zeta potential and particle size of AgNP was determined using a Zetasizer (Nano ZS, ZEN 3600, Malvern) at $25{ }^{\circ} \mathrm{C}$.Concentration of AgNP was measured by ICP-MS ( $\mathrm{X}$ series, Thermo Elemental).

\section{Dissolution of nanosilver}

In this study, humic acid was used to mimic NOM in natural water conditions. NOM solutions were prepared by dissolving humic acid purchased from Sigma Aldrich in DI water. Dissolution of AgNP in DI water in the presence or absence of NOM was measured as total silver using ICPMS (X series, Thermo Elemental) during 5 days. $3 \mathrm{k}$ molecular weight cutoff membrane was used to separate $\mathrm{AgNP}$ with the dissolved silver ions. ICP-MS was used to measure the silver concentration. To confirm the dissolution of AgNP, Cryo transmission electron microscopy (TEM) was used to capture the silver ion dissolution.

\section{Results and discussion}

\section{Characterization of prepared AgNP}

Fig. 1 shows the TEM image of the synthesized AgNP. It exhibits that the shape of nAg is irregularly spherical. The average particle size obtained is $64 \mathrm{~nm}$.

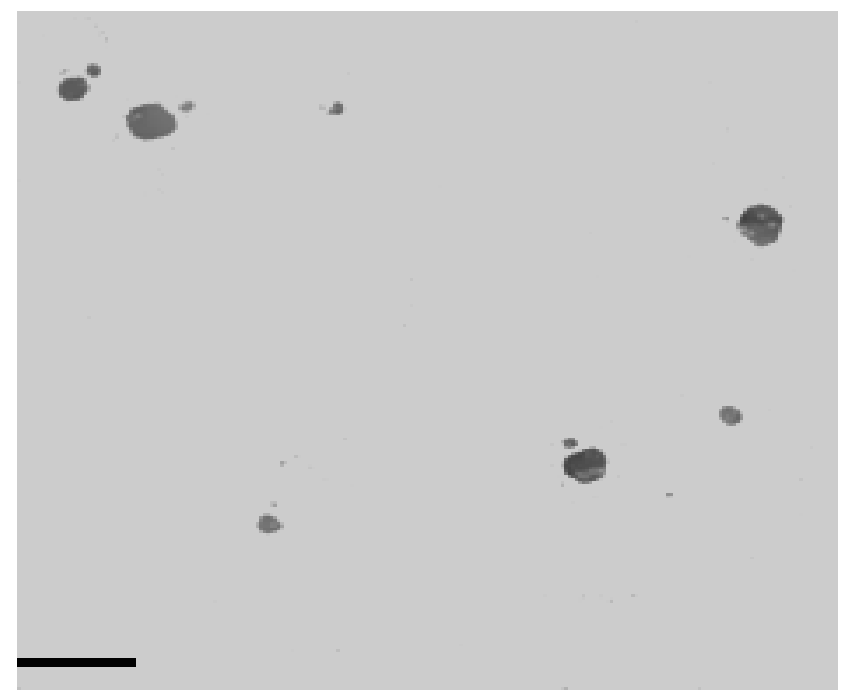

Fig. 1. TEM image of the synthesized AgNP (Black bar=100 nm).

Average particle size and zeta potential of AgNP in solutions with different NOM concentrations were also characterized. As Fig. 2 and Fig. 3 show, the particle size of AgNP did not change significantly due to the addition of NOM. Similar results were found for zeta potential measurement. As previous published literatures have suggested, when AgNP was dispersed in NOM solutions,
NOM molecules can rapidly adsorb on to the surface of nanoparticles, creating a physical barrier between nanoparticles and prevent their aggregation [1-5, 7-17]. This type of repulsion is mainly due to their steric configuration. Zeta potential represents the stability of nanoparticles. In our study, the negative zeta potential values of AgNP indicate that the double layer of AgNP is negatively charged. Adsorption of NOM can screen part of the negative charges. However, NOM carries negative charges, which can replenish the negative charges of AgNP. Our result is consistent with previous studies. Zhang et al. (2012) have reported that particle size and zeta potential of AgNPs stabilized with dextrin, PVP and casein are consistent with the nanoparticles in DI water [15]. Similarly, Li et al. (2010) reported similar findings [7].

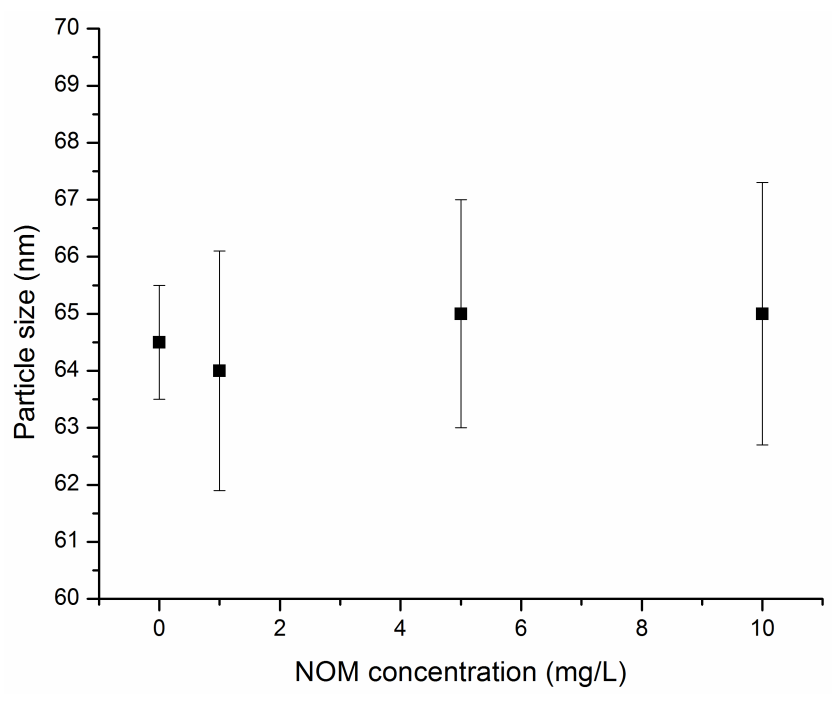

Fig. 2. Particle size of AgNP in NOM solutions.

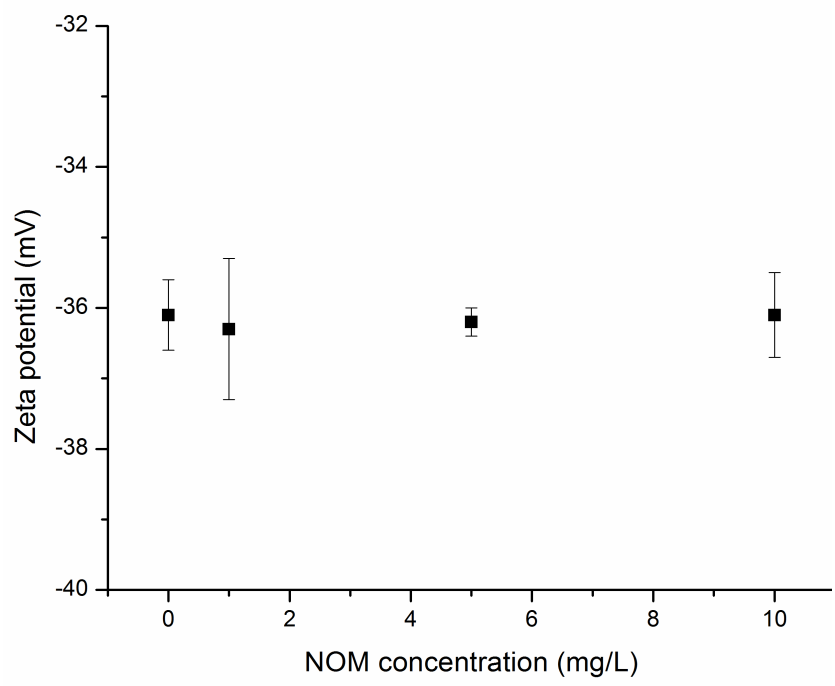

Fig. 3. Zeta potential of AgNP in NOM solutions.

Fig. 4 shows the dissolution kinetics of $\mathrm{nAg}$ in presence of different concentrations of NOM. HA inhibits $\mathrm{nAg}$ dissolution in a dose-dependent manner. Contrary to the dissolution behavior in electrolyte solutions shown in previous studies [9, 15-17], the concentration of dissolved silver in the HA solution decreased over time. Studies have 
suggested that the adsorption of HA molecules can block nAg oxidation sites.

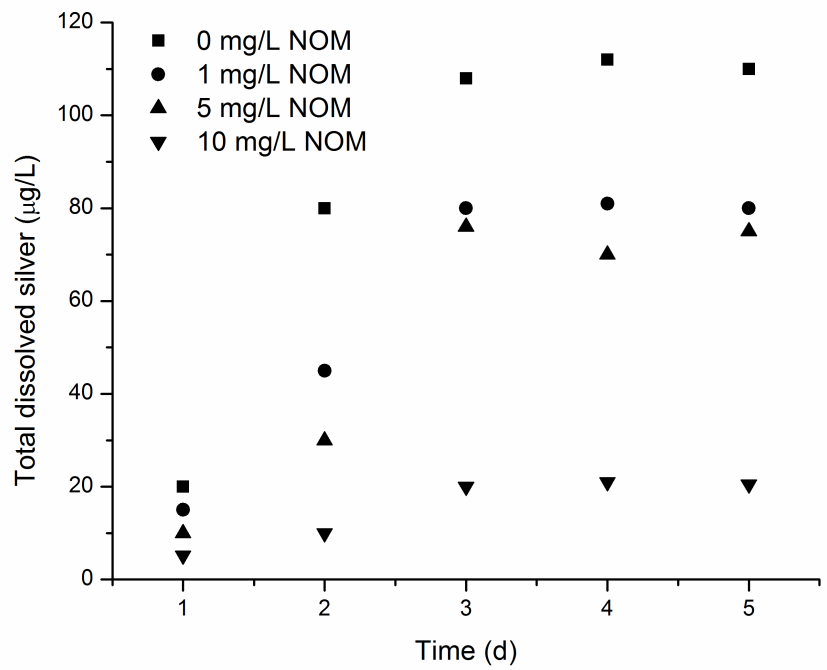

Fig. 4. Dissolution of AgNP in NOM solutions.

Another mechanism proposed that released Ag can be reduced to $\mathrm{nAg}$ via the reducing sites on HA molecules. The dissolution of AgNP was further confirmed by TEM observations. As shown in Fig. 5, the blurry areas represent the dissolved silver ions that are released into the ambient aqueous solution.

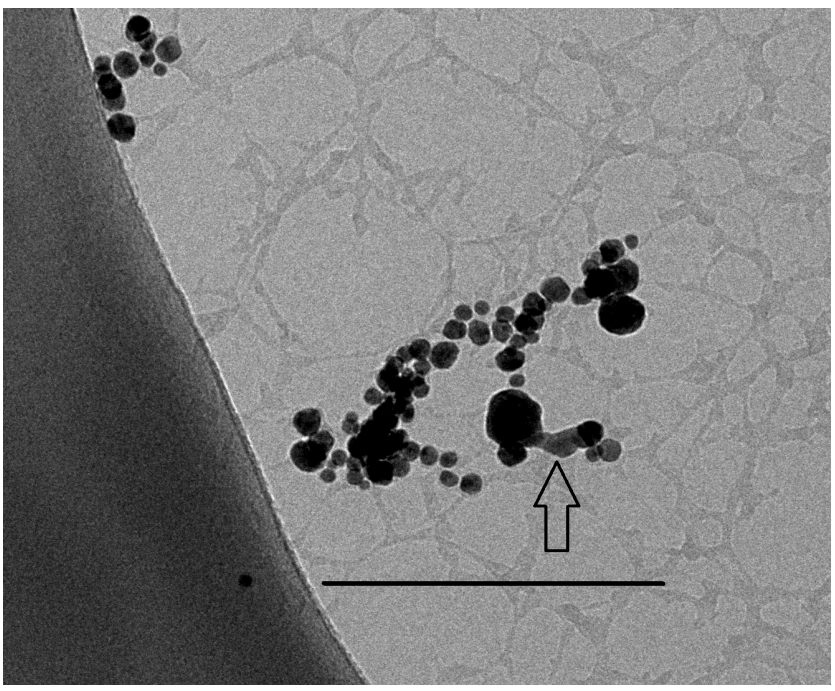

Fig. 5. TEM image of AgNP dissolution (Bar represents $200 \mathrm{~nm}$; blurry areas represent the dissolved silver ions).

\section{Conclusion}

This study investigated the physicochemical properties and dissolution of AgNP in presence of different concentrations of NOM. AgNP was synthesized through Tollens method by reducing the ionic silver into elemental silver by maltose. Particle size and zeta potential measurements show that NOM did not have a significant effect on the particle size and surface charges of AgNP. However, dissolution of AgNP was inhibited in presence of NOM and is decreasing with increasing NOM concentrations.
This research is important to investigate the environmental stability and toxicity of AgNP. Future research will focus on evaluating the toxicity of AgNP on microorganisms.

Reference

1. Zhang, H.; Oyanedel-Craver, V. J. Environ. Eng. 2011, 138, 58. DOI: $10.1061 /($ ASCE)EE.1943-7870.0000460

2. Zhang, H.; Oyanedel-Craver, V. J. Hazard. Mater. 2013, 260, 272. DOI: $10.1016 /$ j.jhazmat.2013.05.025

3. Chen, S.; Zhang, H. Asian J. Chem. 2013, 25, 2909.

4. Jin, X.; Li, M.; Wang, J. Environ. Sci. Technol. 2010, 44 (19), 7321 DOI: $10.1021 / \mathrm{es} 100854 \mathrm{~g}$

5. Gao, J.; Youn, S.; Hovsepyan, A.; Environ. Sci. Technol., 2009, 43, 3322.

DOI: $10.1021 / \mathrm{es} 803315 \mathrm{v}$

6. Zook, J.; MacCuspie, R.; Locascio, L. Nanotoxicology, 2011, 19, 842. DOI: $10.3109 / 17435390.2010 .536615$

7. Li, X.; Lenhart, J.; Walker, H.; Langmuir, 2010, 26 (22), 16690 DOI: $10.1021 /$ la101768n

8. Huynh K., Chen K., Environ. Sci. Technol. 2012, 45, 1021. DOI: $10.1021 / \mathrm{es} 200157 \mathrm{~h}$

9. Liu, J.; Hurt, R.; Environ. Sci. Technol. 2010, 44, 2169. DOI: 10.1021 /es 9035557

10. Kvitek, L.; Vanickova, M.; Panacek, A. J. Phys. Chem., 2009, 113 4296.

DOI: $10.1021 / \mathrm{jp} 711616 \mathrm{v}$

11. Piccapietra, F.; Sigg, L.; Behra, R. Environ. Sci. Technol. 2011, 46, 818.

DOI: $10.1021 / \mathrm{es} 202843 \mathrm{~h}$

12. Dobias, J.; Bernier-Latmani, R. Environ. Sci. Technol. Accepted. DOI: $10.1021 / \mathrm{es} 304023 \mathrm{p}$

13. Chen, S.; Zhang, H.; Asian J. Chem.,2013, 25, 2886

14. Chen, K.; Smith, B.; Ball, W. Environ. Chem. 2012, 26, 201. DOI: $10.1071 /$ EN09112

15. Zhang, H.; Smith, J.; Oyanedel-Craver, V. Water Res., 2012, 46, 691. DOI: $10.1016 /$ j.watres.2011.11.037

16. Li, X.; Lenhart, J.; Walker, H. Langmuir, 2012, 28, 1095. DOI: $10.1021 / 1 \mathrm{a} 202328 \mathrm{n}$

17. Li, X.; Lenhart, J. Environ. Sci. Technol. 2012, 46, 5378 DOI: $10.1021 / \mathrm{es} 204531 \mathrm{y}$

18. Gebauer, J.; Treuel, L. J. Colloid Interf. Sci. 2011, 354, 546 DOI: $10.1016 /$ j.jis. 2010.11 .016

19. Gao, J.; Powers, K.; Wang, Y. Chemosphere, 2012, 89, 96. DOI: $10.1016 /$ j.chemosphere.2012.04.024

20. Chen, S-F.; Zhang, H.; Adv. Nat. Sci.: Nanosci. Nanotechnol., 2012, 3,035006 . DOI: $10.1088 / 2043-6262 / 3 / 3 / 035006$

21. Fabrega, J.; Fawcett, S.; Renshaw, J. Environ. Sci. Technol., 2009, 43 , 7285 .

DOI: $10.1021 / \mathrm{es} 803259 \mathrm{~g}$

\section{Advanced Materials Letters}

Publish your article in this journal

ADVANCED MATERIALS Letters is an international journal published quarterly. The journal is intended to provide top-quality peer-reviewed research papers in the fascinating field of materials peer-reviewed research papers in the fascinating field of materials science particularly in the area of structure, synthesis an applications of materials. All articles are indexed on various databases including DOAJ and are available for download for free. The manuscript management system is completely electronic and has fast and fair peer-review process. The journal includes view articles, research articles, notes, letter to editor and short communications.

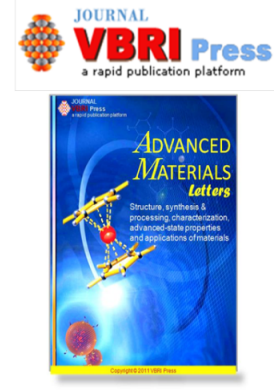

